\title{
TO EVALUATE SAFETY AND EFFECTIVENESS OF KETAMINE-PROPOFOL COMBINATION AND PROPOFOL ALONE IN DIAGNOSTIC RADIOLOGICAL PROCEDURES (MRI) IN PEDIATRIC PATIENTS.
}

\section{Dr. M. Sajith Dr. K. Manogna* Dr. G. Nagaraj} Yadav
M.D Anesthesiology. post graduate ${ }^{\star}$ Corresponding Author

Post graduate.

ABSTRACT along with propofol for pediatric MRI sedation.

Aims And Objectives: to evaluate safety and effectiveness of Ketamine-propofol combination and propofol alone in diagnostic radiological procedures (MRI) in pediatric patients.

Materials And Methods: The present prospective randomized double blinded study was undertaken at Government General Hospital, Tirupati. Pediatric patients aged between 2 to 12 years of both sex, belonging to ASA grade I \& II and posted for elective MRI Brain scan were included in the study.

Results: KP group had significantly more reactions than P group. Recovery time (time taken to achieve modified aldrete recovery score of 9-10) was $37.33 \pm 2.88 \mathrm{~min}$ and $19.6 \pm 2.67 \mathrm{~min}$ in Ketofol group and propofol group respectively. Conclusion: Ketofol is an attractive combination for procedural sedation.

\section{KEYWORDS : Ketamine, Propofol, MRI, Pediatric}

\section{INTRODUCTION:}

There is a growing need for magnetic resonance imaging (MRI) in children for accurate diagnosis and appropriate medical treatment. Children have to lie down motionless inside a noisy claustrophobic environment for duration often longer than $30 \mathrm{~min}$. Therefore, the children need deep sedation for MRI to be completed successfully and without undesired patient movement, discomfort, pain and anxiety.

Most children who need MRI diagnostic procedures have neurological diseases, vascular malformation or oncological tumour growth. Several anesthetic drugs such as intravenous (i.v.) pentobarbiturate, dexmedetomidine, midazolam, fentanyl, propofol and oral chloral hydrate have been used for sedation for pediatric MRI. Of these, propofol is the most favorable and widely used. But deep sedation with high doses of propofol can predispose children to airway obstruction, respiratory depression, hypotension and bradycardia; low doses may cause patient movement necessitating the scan to be repeated. Recent studies have shown that the use of propofol in combination with ketamine for sedation in ambulatory surgery and emergency procedures provided better sedation with lesser side-effects than using propofol alone.

In recent times, small doses of ketamine have been used along with propofol for pediatric MRI sedation. With this regimen, subsequent propofol infusion doses needed are found to be lower than the conventional propofol infusion dose $(100-250 \mathrm{mcg} / \mathrm{kg} / \mathrm{min})$. The hypothesis of this study was that use of low dose of ketamine and propofol would allow MRI scan completion with faster recovery and lower adverse events ${ }^{1}$.

\section{Patients And Methods}

The present prospective randomized double blinded study was undertaken at Government General Hospital, Tirupati. The institutional ethical committee approved the study and written informed consent was obtained from all the patients before being included in the study.

Pediatric patients aged between 2 to 12 years of both sex, belonging to ASA grade I \& II and posted for elective MRI Brain scan were included in the study. Patients belonging to ASA grade III or above, a scan expected to last more than $90 \mathrm{~min}$ patient's refusal, recent upper respiratory infection (URI), children with obstructive sleep apnea, difficult airway or one that required tracheal intubation or laryngeal mask airway, Behavioral problems (i.e., attention deficit hyperactivity disorder), Gastroesophageal reflux disease requiring treatment, Presence of congenital heart disease, A recent upper respiratory infection, pneumonia or episode of acute asthma in the preceding 2 weeks, Patients with known Hypersensitivity to the study drugs, Eggs, Soya beans, History of propofol allergy, patients with increased intracranial, intraocular pressure, Patients with Porphyria, Hepatic dysfunction, Drowsy and comatose patients were excluded from the study.

The patients were randomly allocated in to two groups using computer generated random numbers. Group P (Propofol group; $\mathrm{n}=30$ ) - received $2 \mathrm{mg} / \mathrm{kg}$ of loading dose of Propofol (MCT-ROF) followed by $0.5 \mathrm{mg} / \mathrm{kg}$ iv boluses when it required. Group KP (Ketofol group; $n=30$ ) - received inj.ketamine $\mathrm{lmg} / \mathrm{kg}$ and inj.propofol (MCT-ROF) $\mathrm{lmg} / \mathrm{kg}$ as loading dose followed by $0.5 \mathrm{mg} / \mathrm{kg}$ iv boluses of propofol when it required. Inj.Midazolam $30 \mathrm{mcg} / \mathrm{kg}$ and Inj.Glycopyrrolate $4 \mathrm{mcg} / \mathrm{kg}$ were given as premedication to patients in both groups.

Before enrolment, a thorough pre-anesthetic check of the children was conducted and relevant data collected included body imaging site and any special concerns such as seizure disorders, developmental delay, treatment with antiepileptic medications, or recent upper respiratory infection (URI). Patients completed a demographic questionnaire and patients were explained about the procedure and informed consents were obtained. A pre-procedural fasting of $6 \mathrm{~h}$ for solids, $4 \mathrm{hrs}$ for milk and $2 \mathrm{~h}$ for clear fluids was ensured for the MRI.

In the preinduction room, we secured a 22 or 24 gauge cannula and gave midazolam $0.03 \mathrm{mg} / \mathrm{kg}$ i.v. and glycopyrrolate $0.004 \mathrm{mg} / \mathrm{kg}$ iv to the child $10 \mathrm{~min}$ before the scan. After recording baseline heart rate (HR), systolic blood pressure (SBP), diastolic blood pressure (DBP), respiratory rate (RR) and $\mathrm{SpO} 2$ (oxygen saturation), sleep was induced with bolus of ketamine ( $\mathrm{l} \mathrm{mg} / \mathrm{kg}$ ) and propofol $(\mathrm{l} \mathrm{mg} / \mathrm{kg}$ ) for those who are assigned to 'KP' group and with Propofol $(2 \mathrm{mg} / \mathrm{kg})$ for those who are assigned to ' $\mathrm{P}$ ' group. Level of 
sedation was assessed using University of Michigan Sedation Scale (UMSS, 0 = awake and alert; 1 = minimally sedated: Responds to verbal conversation or sound; $2=$ moderately sedated: Arouses to light tactile stimuli; 3 = deeply sedated: Arouses to deeper physical stimuli; $4=$ unarousable to stimuli).UMSS $=3$ was considered an acceptable level of sedation for starting the scan; if this level was not achieved, propofol boluses of $0.5 \mathrm{mg} / \mathrm{kg}$ were given.

We noted the induction time that is, time to achieve UMSS 3 after the bolus of ketamine and propofol or with propofol alone. The child was appropriately positioned on the scan table using a soft neck roll under the shoulder to slightly extend the neck, supplemental oxygen at 3-4 L/min was given. After ensuring the patency of the airway and adequacy of respiration, the scan was started.

In case of any patient movement, additional propofol bolus $(0.5 \mathrm{mg} / \mathrm{kg})$ was given. On scan completion, awakening time that is, time to attain UMSS $<1$ was recorded. HR, MAP, RR and $\mathrm{SpO} 2$ were recorded at every $5 \mathrm{~min}$ from inducing sedation until the child's awakening. The scan time that is, time from start of scan to its completion was also noted. After awakening, the child was transported to the adjacent recovery room with supplemental oxygen and pulse oximetry. There HR, MAP, RR and SpO2 were monitored. We assessed the child at $15 \mathrm{~min}$ interval until he/she was ready for discharge from medical supervision. The discharge time that is, time to attain modified Aldrete score of $>9$ was recorded after transfer to recovery. All children were followed-up telephonically the next day and the parents asked about any complications such as behavior changes, motor imbalance, respiratory problems, nausea or vomiting.

Data analysis was done using SPSS version 21. Haemodynamics and respiratory data were evaluated using the unpaired t-test for within group comparisons. Numerical data are reported as means +/- standard deviation. Categorical data were analysed using Chi-square test. $\mathrm{P}<$ 0.05 was considered as significant and $\mathrm{P}<0.0001$ as highly significant (HS).

\section{OBSERVATION AND RESULTS}

In present study 60 patients were randomized into two groups of 30 each. The mean age of the patients in ketofol group was $4.93 \pm 2.03$ years and in Propofol group was $5.33 \pm 2.29$ years. Male / female included in our study are 17/13 and 15/15 in Ketofol group and Propofol group respectively. The average weight of the patients in Ketofol and Propofol group are $13.93 \pm 4.58 \mathrm{kgs}$ and $14.43 \pm 3.70 \mathrm{kgs}$ respectively. The ASA status (I/II) of the patient are similar in both Ketofol and Propofol group (14/16 vs 15/15). There was no statistically significant difference between the Ketofol and Propofol group with regard to age, gender, weight, ASA class and were comparable $(\mathrm{P}>0.05)$.

In present study the onset of sedation (Time to achieve UMSS score of 3 ) was $44.76 \pm 5.76 \mathrm{sec}$ in ketofol group and 31.1 \pm 3.09 sec in Propofol group and it was rapid in propofol group and statistically highly significant as $\mathrm{P}=0.0001$ (HS). Duration of procedure in Ketofol group and propofol group was $27.33 \pm 2.15$ min and $28.03 \pm 1.92$ min respectively and were comparable as p > 0.05 (0.189). 1 child (3.33\%) in Ketofol group and 8 (26.67\%) children in Propofol group experienced apnoeic spells and the difference is significantly higher. $\left(\chi^{2}=4.706 ; p=0.03\right)$. On comparison of the two groups with respect to abnormal movements produced, they didn't show any significant difference. $\left(\chi^{2}=0.647 \mathrm{P}=0.421\right)$. Five patients $(16.67 \%)$ in propofol group and two patients $(6.67 \%)$ in Ketofol group moved during scanning and they were treated with topup doses of propofol $0.5 \mathrm{mg} / \mathrm{kg}$ iv.

On comparison of the two groups with respect to emergence of reactions, KP group had significantly more reactions than $\mathrm{P}$ group ( 9 children vs one child) $\left(\chi^{2}=7.68 ; \mathrm{P}<0.05\right)$. Recovery time (time taken to achieve modified aldrete recovery score of 9-10) was $37.33 \pm 2.88 \mathrm{~min}$ and 19.6 $\pm 2.67 \mathrm{~min}$ in Ketofol group and propofol group respectively. Recovery was faster in Propofol group when compared to Ketofol group and it was statistically highly significant as $p=0.0001$. Baseline mean arterial pressure in Ketofol and propofol group were $84.3 \pm 5.81 \mathrm{~mm}$ of $\mathrm{Hg}$ and $83.7 \pm 6.59 \mathrm{~mm}$ of $\mathrm{Hg}$ respectively. Baseline heart rate in Ketofol and propofol group were $95.3 \pm 9.93$ and $93.8 \pm 9.73$ respectively. In our study there was no statistically significant difference in baseline haemodynamic parameters like mean arterial pressure, heart rate between Ketofol and propofol group and were comparable as $\mathrm{p}>0.05$.

Before start of the scan, two groups didn't show significant difference with respect to mean arterial pressure $(p>0.05)$. After induction, at every minute, P group showed significantly very low mean arterial pressure than KP group. $(p<0.001)$ After recovery from the drug influence again two groups mean arterial pressure don't showed significant difference. ( $p>0.05$ ) In present study, at the end of the procedure mean arterial pressure was significantly lower in propofol group when compared to ketofol group ( $74.6 \pm 4.52 \mathrm{~mm}$ of $\mathrm{Hg}$ vs $82.4 \pm 5.58$ $\mathrm{mm}$ of $\mathrm{Hg}, \mathrm{p}=0.0001)$. In our study four (13.3\%) patients in propofol group and no patients in Ketofol group developed hypotension. All episodes of hypotension were treated with $10 \mathrm{ml} / \mathrm{kg}$ of crystalloid boluses in propofol group. None of the patients required vasopressors for correction of hypotension (Table 1 Graph 1).

Table 1: Showing The Comparison Of Mean Arterial Pressure In The Two Groups

\begin{tabular}{|l|l|l|l|}
\hline Mean arterial pressure \\
\hline Duration & KP group & P group & p-value \\
\hline 0 minutes & $84.3 \pm 5.81$ & $83.7 \pm 6.59$ & 0.709 \\
\hline 5 minutes & $83.4 \pm 5.48$ & $69.7 \pm 6.19$ & $0.0001(\mathrm{HS})$ \\
\hline 10 minutes & $84.0 \pm 5.70$ & $71.6 \pm 6.39$ & $0.0001(\mathrm{HS})$ \\
\hline 15 minutes & $83.2 \pm 6.01$ & $72.4 \pm 6.35$ & $0.0001(\mathrm{HS})$ \\
\hline 20 minutes & $82.9 \pm 6.01$ & $77.7 \pm 4.85$ & $0.0005(\mathrm{HS})$ \\
\hline 25 minutes & $83.2 \pm 5.50$ & $75.1 \pm 4.82$ & $0.0001(\mathrm{HS})$ \\
\hline 30 minutes & $83.0 \pm 5.71$ & $73.9 \pm 4.55$ & $0.0001(\mathrm{HS})$ \\
\hline 35 minutes & $82.4 \pm 5.58$ & $74.6 \pm 4.52$ & $0.0001(\mathrm{HS})$ \\
\hline Recovery & $82.1 \pm 5.61$ & $82.8 \pm 6.22$ & 0.649 \\
\hline
\end{tabular}

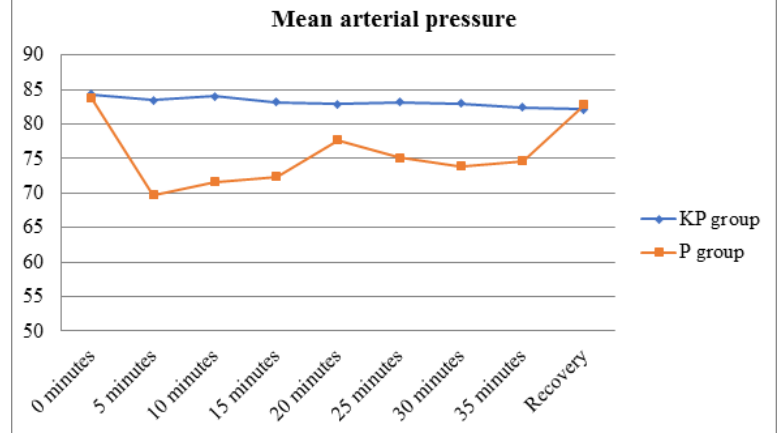

Graph 1 Line Diagram Showing The Comparison Of Mean Arterial Pressure

During pre induction, two groups didn't show any significant difference with respect to heart rate $(p>0.05)$. After induction at every minute, $\mathrm{P}$ group showed significantly very low heart rate than KP group $(p<0.001)$. After recovery from the drug influence again two groups heart rate don't showed significant difference ( $p>0.05$ ) (Table 2 Graph 2)

In this study one patient in propofol group one patient (3.3\%) developed bradycardia during scan and none of the patients 
in Ketofol group developed bradycardia. It was corrected with inj.Atropine $0.2 \mathrm{mg}$ iv. In our study none of the patients in either group developed tachycardia during the procedure.

Table 2: Showing The Comparison Of Heart Rate In The Two Groups

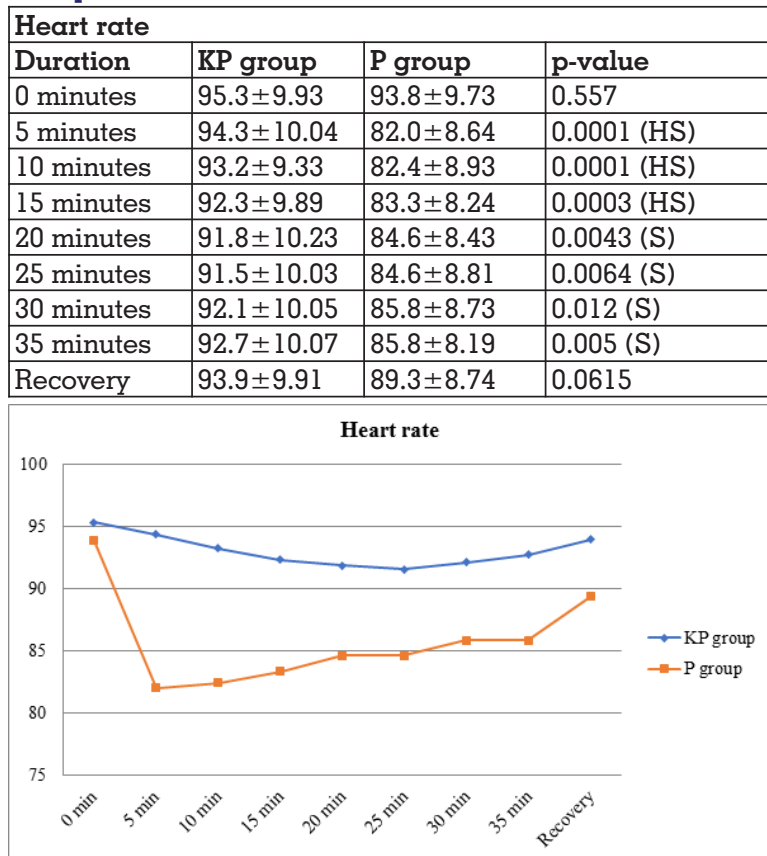

Graph 2 Line Diagram Showing The Comparison Of Heart Rate

Baseline respiratory rate in Ketofol and propofol group were $21.1 \pm 2.40$ and $20.8 \pm 2.40$ respectively. Baseline oxygen saturation in Ketofol and propofol group were $97.9 \pm 1.05$ and $97.7 \pm 1.28$ respectively In our study there was no statistically significant difference in respiratory rate and oxygen saturation between Ketofol and propofol group and were comparable as p $>0.05$ (Table 3 graph 3).

Table 3 Showing The Comparison Of Respiratory Rate In The Two Groups

\begin{tabular}{|l|l|l|l|}
\hline \multicolumn{4}{|l|}{ Respiratory rate } \\
\hline Duration & KP group & P group & p-value \\
\hline 0 minutes & $21.1 \pm 2.40$ & $20.8 \pm 2.40$ & 0.630 \\
\hline 5 minutes & $21.5 \pm 2.16$ & $20.5 \pm 2.35$ & 0.09 \\
\hline 10 minutes & $21.0 \pm 2.29$ & $20.0 \pm 1.73$ & 0.06 \\
\hline 15 minutes & $20.3 \pm 1.99$ & $19.5 \pm 1.74$ & 0.102 \\
\hline 20 minutes & $19.7 \pm 1.47$ & $19.4 \pm 2.06$ & 0.519 \\
\hline 25 minutes & $19.5 \pm 1.59$ & $19.0 \pm 1.79$ & 0.257 \\
\hline 30 minutes & $18.7 \pm 1.51$ & $18.0 \pm 2.00$ & 0.131 \\
\hline 35 minutes & $18.5 \pm 1.48$ & $17.6 \pm 2.50$ & 0.095 \\
\hline Recovery & $19.2 \pm 1.42$ & $18.7 \pm 2.71$ & 0.374 \\
\hline
\end{tabular}

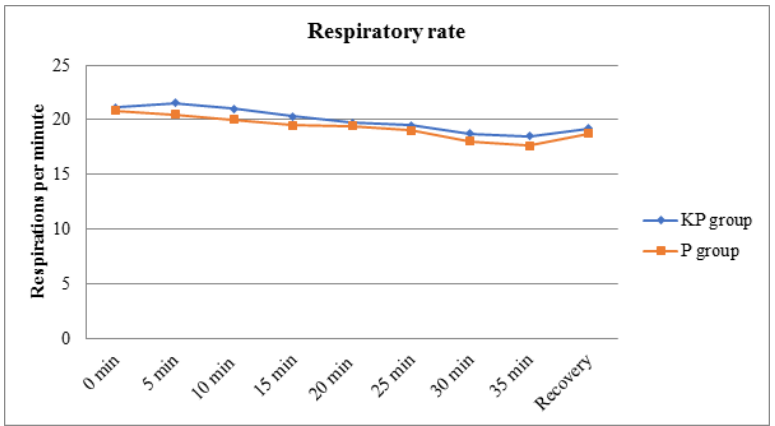

Graph 3: Line Diagram Showing The Comparison Of Respiratory Rates
Respiratory rates of the two groups didn't vary much before induction, after induction and after recovery $(p>0.05)$. None of the patients in either group developed bradypnoea during scanning Oxygen saturation of two groups didn't vary much before induction, after induction and after recovery $(p>0.05)$ (Table 4 Graph 4). 2 patients in Propofol developed desaturation at T5 (Spo2 95\%) and they are corrected with increase of Oxygen flow rate $(3 \mathrm{lt} / \mathrm{min}$ ). No patients were required external manipulation of airway or supraglottic airway or tracheal intubation for hypoxemia. No patients in Ketofol group developed hypoventilation or desaturation. Eight patients in Propofol group (26.6\%) and 1 patient in Ketofol group (3.3\%) developed apnoeic episodes during procedure.

Table 4: Showing The Comparison Of $\mathrm{SpO} 2$ In The Two Groups

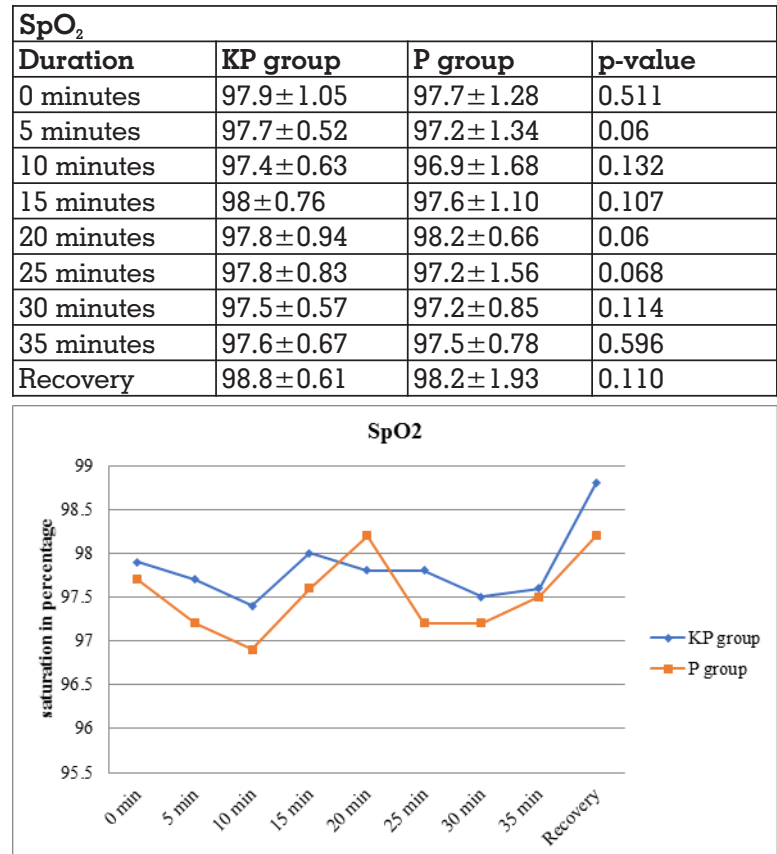

Graph 4: Line Diagram Showing The Comparison Of SpO2

\section{DISCUSSION}

Propofol (2,6 di-isopropylphenol) is a highly lipophilic compound that exhibits rapid distribution from the blood to the subcutaneous fat and the central nervous system compartments with subsequent redistribution and metabolic clearance. It is considered to be a short acting andesthetic that is both rapid in its onset and short in duration after cessation. Because of these pharmacokinetic and dynamic characteristics, propofol became a frequently administered drug for induction and/or maintenance of anaesthesia in children and more recently, in neonates. ${ }^{2-7}$

Owing to side effects of propofol in children J Vanderhaegen et $\mathrm{al}^{8}$. strongly dissuade the use of continuous administration of propofol in the first weeks of life and suggest to limit its use in this specific population to single bolus administration for induction of ancesthesia or single bolus administration for procedural sedation. In contrast, a single intravenous bolus administration might be a very useful tool for short time procedural sedationKetofol is the combination of ketamine and propofol in various concentrations which is used for several procedures. Ketamine, a neuroleptic anesthetic agent, works on thalamocortical and limbic N-methyl-D-aspartate (NMDA) receptors ${ }^{9,10}$.

It can be given through intravenous or intramuscular routes. Ketamine stimulates the cardiorespiratory system. A direct 
art

effect increases cardiac output, arterial blood pressure, heart rate and central venous pressures. Therefore, it is a valuable agent for hypotensive or hypovolemic patients, but a less desirable agent in patients with ischemic heart disease or raised pulmonary vascular pressure.

The dose regimen of ketofol used in our study were similar to that used by Divya Sethi, Madhu Gupta et al ${ }^{1}$. Group KP (Ketofol group; $\mathrm{n}=30$ ) - received inj.ketamine $\mathrm{lmg} / \mathrm{kg}$ and inj.propofol $\mathrm{lmg} / \mathrm{kg}$ as loading dose followed by $0.5 \mathrm{mg} / \mathrm{kg}$ iv boluses of propofol when it required. The dose regimen of propofol used in our study were similar to that used by Eun Jung Kim et $\mathrm{al}^{11}$. Group P (Propofol group; $\mathrm{n}=30$ ) - received 2 $\mathrm{mg} / \mathrm{kg}$ of loading dose of Propofol followed by $0.5 \mathrm{mg} / \mathrm{kg}$ iv boluses when it required.

In the study conducted by Divya Sethi, Madhu Gupta et al ${ }^{1}$, they had given midazolam $0.05 \mathrm{mg} / \mathrm{kg}$ iv to the child $30 \mathrm{~min}$ before the scan similar to our study which was given as premedication to calm the children and allay any anxiety while waiting for their scan and however, it is possible that midazolam premedication could have also enhanced the success of the sedation regimen. It also helps to decrease the induction doses of propofol and ketamine.

In present study the onset of sedation was rapid in ketofol group when compared to propofol group (31.1 \pm 3.09 sec vs $44.76 \pm 5.76 \mathrm{sec})$ and it was statistically highly significant $(\mathrm{P}=$ 0.0001 ). Vesna Marjanović, Ivana Budić et $\mathrm{al}^{12}$ in their study got the similar finding with regards to onset of action. Before start of the scan, two groups didn't show significant difference with respect to mean arterial pressure $(p>0.05)$. After induction, at every minute, group $\mathrm{P}$ showed significantly very low mean arterial pressure than KP group. $(p<0.001)$

At the end of the procedure, mean arterial pressure was significantly lower in propofol group when compared to ketofol group (74.6 $\pm 4.52 \mathrm{~mm}$ of $\mathrm{Hg}$ vs $82.4 \pm 5.58 \mathrm{~mm}$ of $\mathrm{Hg}, \mathrm{p}=$ 0.0001 ). After recovery from the drug influence again two groups mean arterial pressure didn't show significant difference. $(p>0.05)$

In this study four (13.3\%) patients in propofol group and no patients in Ketofol group developed hypotension. All episodes of hypotension were treated with $10 \mathrm{ml} / \mathrm{kg}$ of crystalloid boluses in propofol group. None of the patients required vasopressors for correction of hypotension. Similar changes in mean arterial blood pressure were observed in a study conducted by Gamal T. Yousef, Khalid M. Elsayed et al., ${ }^{13}$ on clinical comparison of ketofol (ketamine and propofol admixture) versus propofol as an induction agent on quality of laryngeal mask airway insertion and haemodynamic stability in children where they found that the mean blood pressure was significantly decreased in the P group compared to the KP group at all measurement points $(P<0.05)$ and was significantly lower than the basal level in the $\mathrm{P}$ group $(\mathrm{P}<$ 0.005).

In our study one patient in propofol group (3.3\%) developed bradycardia during scan and none of the patients in Ketofol group developed bradycardia. It was corrected with inj.Atropine $0.2 \mathrm{mg}$ iv. In our study none of the patients in either group developed tachycardia during the procedure. Similar changes in heart rate were observed in a study conducted by Gamal T. Yousef, Khalid M. Elsayed et al., ${ }^{13}$ on clinical comparison of ketofol (ketamine and propofol admixture) versus propofol as an induction agent on quality of laryngeal mask airway insertion and haemodynamic stability in children where they found that the heart rate was significantly decreased in the $\mathrm{P}$ group $(\mathrm{P}<0.05)$, while it remained comparable to basal level in the KP group at all measurement points. The difference between the two groups was found to be statistically significant $(\mathrm{P}<0.005)$.

In previous studies conducted by Âkin A, Esmaoglu A, Tosun Z, et al. ${ }^{14}$ showed that there were no cases of desaturation in the ketofol group, but in the propofol group 4/30 experienced desaturation and 6/30 had apnea and our study results correlate with these studies with regards to respiratory rate variations.

In our study results were in line with those reported in studies by Vesna Marjanović, Ivana Budic et al., ${ }^{12}$ where they observed that the shortest period of recovery after performing deep sedation was registered in propofol group $(p<0.001)$ when compared to ketofol group Bradycardia was observed in one patient $(3.3 \%)$ in propofol group and none in ketofol group which was similar to that of studies conducted by Burton $\mathrm{JH}$, et al., ${ }^{15}$ and Gamal T. Yousef \& Khalid M. Elsayed et al., ${ }^{13}$ and was corrected with inj.Atropine $0.2 \mathrm{mg}$ iv.

In present study, eight patients in Propofol group (26.6\%) and one patient in Ketofol group (3.3\%) developed apnoeic episodes during procedure which was statistically significant $(\mathrm{P}=0.03)$ And similar results were obtained in the study conducted by Gamal T. Yousef \& Khalid M. Elsayed et al., ${ }^{13}(\mathrm{P}$ $<0.05$ ). Two patients in Propofol group developed desaturation at T5 (Spo2 95\%) and they were corrected by increasing oxygen flow rate to $5 \mathrm{lit} / \mathrm{min}$.

\section{CONCLUSION}

Ketofol is an attractive combination for procedural sedation as it results in improved haemodynamic stability with less prolonged apnoea, better sedation, and enhanced patient comfort and safety when compared to propofol alone.

\section{REFERENCES:}

1. Divya Sethi, Madhu Gupta, Shalini Subramanian. A randomized trial evaluating low doses of propofol infusion after intravenous ketamine for ambulatory pediatric magnetic resonance imaging. Vol. 8, Issue 4, OctoberDecember 2014 Saudi Journal of Anesthesia

2. Murat I, Billard V, Vernois J, et al. Pharmacokinetics of propofol after a single dose in children aged 1-3 years with minor burns. Comparison of three data analysis approaches Anesthesiology 1996; 84: 526-32.

3. Saint-Maurice C, Cockshott ID, Douglas EJ, et al. Pharmacokinetics of propofol in young children after a single dose. BrJ Anaesth 1989; 63: 667-70.

4. Ghanta S, Abdel-Latif ME, Lui K, Ravindranathan H, Awad J, Oei J. Propofol compared with the morphine, atropine, and suxamethonium regimen as induction ag ents for neonatal endotracheal intubation: a randomized, controlled trial. Pediat rics 2007; 119: el248-55

5. Papoff P, Mancuso M, Caresta E, Moretti C. Effectiveness and safety of propofol in newborn infants. Pediatrics 2008; 121: 448-9.

6. Veyckemans F. Propofol for intubation of the newborn? Paediatr Anaesth 2001,11:630-1.

7. Wolf AR, Potter F. Propofol infusion in children: when does an anesthetic tool become an intensive care liability? Paediatr Anaesth 2004; 14: 435-8.

8. Dalal PG, Murray D, Cox T, McAllister J, Snider R. Sedation and anesthesia protocols used for magnetic resonance imaging studies in infants: Provider and pharmacologic considerations. Anesth Analg 2006;103:863-8.

9. Amornyotin S (2014) Sedative and analgesic drugs for gastrointestinal endoscopic procedure. J Gastroenterol Hepatol Res 3(7): 11331144

10. Pandit JJ (2011) Intravenous anesthetic agents. Anesth Intens Care Med 12(4): 144-150.

11. Eun Jung Kiml, Youn Yi Jo2, and Hae Keum Kill Optimal sedative dose of propofol to start MRI in children with cerebral palsy Korean J Anesthesiol 2011 September 61(3): 216-219.

12. Vesna Marjanović, Ivana Budić . Efficacy of different anesthetics for achieving deep sedation during magnetic resonance imaging in children (anesthetics for a deep sedation during magnetic resonance imaging); ISSN 2466-488X (Online) doi:10.5937/sjait1608219M;SJAIT 2016/5-6

13. Gamal T. Yousef and Khalid M. Elsayed. A clinical comparison of ketofol (ketamine and propofol admixture) versus propofol as an induction agent on quality of laryngeal mask airway insertion an hemodynamic stability in children Anesth Essays Res. 2013 May-Aug;7(2):194-199;

14. Akin A, Esmaoglu A, Tosun Z, et al. Comparison of propofol with propofolketamine combination in pediatric patients undergoing auditory brainstem response testing. Int J Pediatr Otorhinolaryngol. 2005; 69:1541-1545

15. Burton JH, et al. Propofol for emergency department procedural sedation and analgesia: A tale of three centers. Acad Emergy Med 2006;13:24-30. 